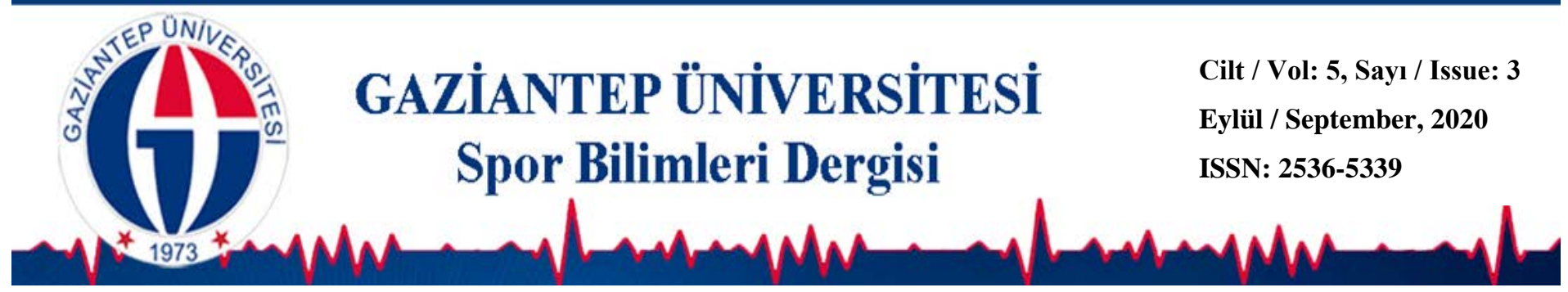

\title{
Rekreatif Egzersiz ve Motivasyon: Fitness Merkezleri Üzerine Amprik Bir Çalışma
}

\author{
Pınar GÜZEL ${ }^{1 *}$ (iD \\ Melike ESENTAŞ ${ }^{1}$ iD \\ ${ }^{1}$ Manisa Celal Bayar Üniversitesi, Spor Bilimleri Fakültesi, MANISA \\ ${ }^{2}$ Ankara Üniversitesi, Sağlık Bilimleri Enstitüsü, ANKARA
}

Özge YAVAŞ TEZ ${ }^{2}$ D

DOI: $10.31680 /$ gaunjss.712108

Orijinal Makale / Original Article

Geliş Tarihi / Received: 31.03.2020
Kabul Tarihi / Accepted: 29.06.2020

Öz

Bu araştırma "Rekreatif egzersiz amaçlı katılımda etkili olan motivasyon faktörlerinin fitness merkezi katılımcıları üzerindeki etkilerinin incelenmesi” amacıyla yapılmıştır. Çalışmanın örneklem grubunda toplam 1242 fitness merkezi katılımcısı yer almıştır. Çalışmada veri toplama aracı olarak, "Egzersiz Motivasyon Anketi” (REMM) kısa formu kullanılmıştır. Verilerin analizi için betimsel istatistikler, güvenirlik analizi, MANOVA analizi kullanılmıştır. MANOVA analiz sonuçları, cinsiyet ve yaş değişkeninin "REMM" nin tüm alt boyutlarında (sağlık, rekabet, vücut ve dış görünüm, sosyal ve eğlence, beceri gelişimi) temel etkisinin anlamlı olduğu belirlenmiştir. Gelir düzeyi değişkenine göre "rekabet" ve "beceri gelişimi" alt boyutlarının temel etkisinin anlamlı olduğu belirlenmiştir. Eğitim düzeyi ve egzersiz türü, egzersiz süresi değişkenlerine göre "rekabet" alt boyutu hariç tüm alt boyutlar üzerinde temel etkisinin anlamlı olduğu belirlenmiştir. Besin takviyesi değişkenine göre REMM'in "sağlık" ile "sosyal ve eğlence" alt boyutları hariç tüm alt boyutları üzerindeki temel etkisinin anlamlı olduğu belirlenmiştir. Rekreatif egzersiz amaçlı katılımda bireysel farklılıkların motivasyon faktörleri üzerinde etkisi olduğu ve bu farklılıkların katılımcıların negatif ya da pozitif tutumlarından kaynaklandığı söylenebilir.

Anahtar Kelimeler: Serbest Zaman, Motivasyon, Fitness

\section{Recreational Exercise and Motivation: An Empirical Study on Fitness Centers}

\begin{abstract}
This research was conducted "to examine the effects of motivation factors that are effective in participation for recreational exercise purposes on fitness center participants". The sample group of the study included 1242 fitness center participants. In the study, "Recreational Exercise Motivation Measure" (REMM) short form was used as data collection tool. Descriptive statistics, reliability analysis and MANOVA analysis were used for data analysis. The results of MANOVA analysis determined that the main effect of gender and age variables on all subdimensions of REMM (health, competition, body and appearance, social and entertainment, skill development) is significant. According to the income level variable, the main effect of "competition" and "skill development" subdimensions was determined to be significant. It was determined that the main effect of education level and exercise type on all sub-dimensions, except for "competition" sub-dimension, was significant according to the exercise duration variables. According to the nutritional supplement variable, the main effect of REMM on all subdimensions, except for "health" and "social and entertainment" sub-dimensions, was found to be significant. It can be said that individual differences in participation for recreational exercise have effect on motivation factors and these differences are caused by the negative or positive attitudes of the participants.
\end{abstract}

Keywords:Leisure time, Motivation, fitness

\footnotetext{
* Sorumlu Yazar: Özge YAVAŞ TEZ
}

E-mail: ozgeyavast@hotmail.com.tr 


\section{Giriş}

Günümüzde bireylerin rekreatif etkinliklere katılım sağlaması, zihinsel, psikolojik ve fiziksel yönden sağlıklı ve yenilenmiş bir birey olmasına katkı sağlamaktadır. Bu durum, serbest zaman kavramını her kesimden birey için önemli ve hayatlarının odak noktasında tutmalarının gerektiğini göz önüne sermektedir. Her kesimden bu bireylerin serbest zamanlarını değerlendirmek ciddi bir sorun olarak görülse de, bireyler, çalışma dışındaki serbest zamanlarında dinlenmekten ve sevdikleriyle gönüllü olarak tercih ettikleri etkinliklere katılmaktan da keyif almaktadırlar (Şahin vd., 2009: 62). Broadhurst (2001), Robert (2006) ve Tezcan (1994) serbest zaman kavramını iş, uyku ve zorunluluklar dışında kalan zaman dilimi olarak ifade ederken, bu zaman diliminde insanların gönüllü olarak tercih ettikleri aktiviteleri de serbest zaman etkinlikleri olarak belirtmişlerdir. Serbest zaman etkinlikleri, bireylerin gündelik mutlulukları için önem arz ederken, bu süreç içerisinde gönüllü olarak seçilen etkinlikler bireyin motivasyonunu artırarak keyif ve haz duymasına önemli bir katkı sağlamaktadır. (Broughton ve Beggs 2007). Bir başka çalışmada ise Esentaş (2018) serbest zaman etkinliklerini, bireylerin serbest zamanlarında gönüllü olarak bireysel ya da grup halinde monoton yaşam kalıplarından çıkarak katılım sağladığı, motivasyonlarının artmasını sağlayan eğlenerek, keyif alarak yaparak yaşayarak öğrenmelerini sağlayan etkinlikler bütünü olarak ifade etmektedir.

Bireylerin sağlıklı bir yaşam sürebilmek, kendilerini zinde hissetmek egzersiz yapmak için tercih ettikleri yerlerden bir tanesi de fitness merkezleridir. Türk Dil Kurumu (TDK) fitness kavramını sağlıklı yaşam olarak tanımlamaktadır (TDK, 2020). Fitness yapılan egzersizler aracılığıyla kasların aletlerle ya da aletsiz çalıştırılması, sıkılaştırılması ve güçlendirilmesi hedeflenmektedir. Böylelikle bireylerin kas grupları kondisyon kazanırken, ruh ve beden sağlığı da düzene girerek bireylerin egzersizler aracılığıyla motivasyonel olarak olumlu katkı sağladığı düşünülmektedir. Rekreasyonel spor hizmeti hazırlayıp sunan bir işletmenin veya fitness merkezinin rekabet avantajı kazanacağı en belirgin yol, rakiplerden daha nitelikli hizmet üretmek ya da başka bir ifadeyle, tüketici beklentilerine cevap verebilmektir (Demirel, 2013). Zaman içerisinde işletmeler bunun farkında olarak serbest zamanda katılım sağlanan etkinlikleri geliştirip ticari bir sektör haline getirmiş ve kişilere yönelik talebi değerlendirerek doyum noktasına ulaşmalarını sonrasında ise motivasyon düzeylerini arttırmaya yönelik amaca yönelmişlerdir. TDK (2020) sözlüğünde motivasyon kelimesi isteklendirme, güdüleme olarak tanımlanmıştır. Carroll ve Alexandris (1997) 
ise motivasyon kelimesini kişiyi bir davranışı yapmaya yönlendiren içsel ve dışsal uyarıcılar olarak tanımlamaktadır. Brunet ve Sabiston (2011), motivasyon bireylerin davranışlarını başlatmasına veya sürdürmesine yardımcı olan bir faktör olarak görülmektedir. Her birey farklı rekreasyonel etkinliklerle motivasyon gerçekleştirmekte dir. Motivasyon bireyi davranışa iten, bu davranışın devamlıı̆ını ve şiddetini belirleyen, davranışları yönlendiren duyuşsal bir faktör olarak ortaya çıkmaktadır (Yılmaz ve Çavaş, 2007). Alan yazında yapılan çalışmalara bakıldığında; serbest zamanlarda yapılan rekreatif egzersizlerin fizyolojik ve psikolojik açıdan yaşam kalitesine olumlu katkılar sağladığı görülmektedir (Çağlar ve ark, 2019; Mutlu ve ark., 2011; Hamer et all, 2002; Aydın ve Yaşartürk, 2017; Kaya, 2019).

Bu bağlamda bu araştırmada, rekreatif egzersiz amaçı katıımda etkili olan motivasyon faktörlerinin fitness merkezi katılımcıları üzerindeki etkilerinin incelenmesi amacıyla yapılmıştır.

\section{Yöntem}

\section{Evren ve Örneklem}

Araştırmanın çalışma grubunu, İzmir ilinde yaşayan yaşları 17 ile 62 arasında değişen ve kolayda örnekleme metoduyla seçilen 564 kadın (Ortyaş=29,48 10,39 ) 678 erkek (Ortyaş $=28,64 \pm 9,02$ ) toplam 1242 yetişkin (Ortyaş= 29,02 $\pm 9,67$ ) oluşturmaktadır.

\section{Veri Toplama Araçları}

Egzersiz Motivasyon Anketi (Remm): Rogers (2000) tarafından 90 madde ve 8 alt boyut olarak geliştirilen ve Rogers ve Morris (2003) tarafından 73 madde ve 8 alt boyut olmak üzere kısa formu oluşturulan ölçeğin kısa formu üzerinde Gürbüz, Aşçı ve Çelebi (2006) tarafından Türkçe geçerlik ve güvenirlik çalışması yapılmıştır. Ölçekte bireyleri rekreasyonel amaçlı fiziksel aktiviteye yönlendiren nedenleri belirlemeye yönelik (1) sağlık (23-31-30-22-20-19-10-32-37-6-18-28-40-58-55-29-6521-11-52-46-36), (2) rekabet (47-45-48-42-66-44-27-56-33-15-57-4-25-61), (3) vücut ve dış görünüm (12-26-14-60-34-49-59-41-8-13-54), (4) sosyal ve eğlence (62-53-3863-35-7-24-51-5-43-9), (5) beceri gelişimi (2-3-1-16-50-39-17-64) olmak üzere 5 alt boyut ve 66 madde yer almaktadır. Ölçek "kesinlikle katılmıyorum (1)........, kesinlikle katılıyorum (5)" şeklinde 5"li Likert tipi ölçek üzerinde değerlendirilmektedir. Gürbüz vd. (2006) gerçekleştirdiği Türkçe geçerlik ve güvenirlik çalışmasında anketin Cronbach Alpha iç tutarlılık katsayıları "sağlık" alt boyutu için 0,93, "rekabet" alt 
boyutu için 0,88 , "vücut ve dış görünüm" alt boyutu için 0,85 , "sosyal ve eğlence" alt boyutu için 0,88 ve "beceri gelişimi" alt boyutu için 0,84 olarak bulunmuştur. Ayrıca ölçeğin Rogers (2000) tarafından geliştirildiği şekli ile orijinal ismine bağlı kalınarak Dinç ve Yavaş-Tez (2019) tarafından REMM (Recreational Exercise Motivation Questionnaire/ Rekreasyonel Egzersize Motivasyon Ölçeği) olarak 7-17 yaş çocuklarda kullanılmak üzere tek faktör ve 10 maddelik kısa formu oluşturulmuştur. Mevcut araştırmada Gürbüz, Aşçı ve Çelebi (2006) tarafından geçerlik ve güvenirlik çalışması yapılan 5 alt boyut ve 66 maddeden oluşan ölçek formu kullanılmıştır. Mevcut araştırmada ölçeğe ilişkin Cronbach Alpha iç tutarlılık katsayıları "sağlık" alt boyutu için 0,85 , "rekabet" alt boyutu için 0,78 , "vücut ve dış görünüm" alt boyutu için 0,76 , "sosyal ve eğlence" alt boyutu için 0,74 ve "beceri gelişimi" alt boyutu için 0,71 olarak bulunmuştur.

\section{Verilerin Toplanması}

Araştırmada kullanılan veri toplama araçlarının uygulamasında, İzmir'in farklı semtlerinde yer alan fitness merkezi sahiplerinden gerekli izinlerin alınarak uygulanmıştır. Katıımcılara araştırma ile ilgili gerekli bilgilendirme yapılarak gönüllü olarak katılmak isteyenlere Gönüllü Onam Formu doldurtularak ölçek formları uygulanmıştır. Her bir ölçeğin uygulaması yaklaşık 10 dakika sürmüştür.

\section{Verilerin analizi}

Araştırma kapsamında yapılan istatistiksel analizler, IBM SPSS 24 istatistik paket programı aracılığıyla gerçekleştirilmiştir. Verilerin parametrik testlerin ön şartlarını sağlayıp sağlamadığına çarpıklık ve basıklık (verilerin normal dağılım durumu) değerleri, Kolmogorov-Smirnov ve Levene (varyansların eşitliği) testi sonuçları incelenerek karar verilmiştir (Büyüköztürk vd., 2012). Verilerin analizi için betimsel istatistikler, normallik ve güvenirlik analizleri ve MANOVA testleri kullanılmıştır.

\section{Bulgular}

Araştırmanın hipotezleri kapsamında yapılan betimsel istatistikler ve MANOVA testlerine ait bulgular Tablo 1'de verilmiştir. 
Tablo 1. Cinsiyet Değişkenine Göre MANOVA Sonuçları (REMM)

\begin{tabular}{lllllll}
\hline & \multicolumn{5}{c}{ Kadın (n=564) } & \multicolumn{1}{c}{ Erkek (n=678) } \\
\hline & Sağlık & $\overline{\mathbf{x}} \pm$ & ss & $\overline{\mathbf{x}} \pm$ & $\mathbf{s s}$ & $\mathbf{p}$ \\
\hline \multirow{2}{*}{ REMM } & $3,75 \pm$ &, 580 & $3,85 \pm$ &, 598 &, 002 \\
& Rekabet & $3,55 \pm$ &, 643 & $3,65 \pm$ &, 665 &, 006 \\
& Vücut ve Dış Görünüm & $3,57 \pm$ &, 687 & $3,74 \pm$ &, 684 &, 000 \\
& Sosyal ve Eğlence & $3,76 \pm$ &, 600 & $3,83 \pm$ &, 622 &, 023 \\
& Beceri Gelişimi & $3,71 \pm$ &, 683 & $3,91 \pm$ &, 648 &, 000 \\
\hline
\end{tabular}

Yapılan çoklu varyans analizine göre, araştırmaya katılan bireylerin "cinsiyet" değişkenine göre REMM'in tüm alt boyutları üzerindeki temel etkisinin anlamlı olduğu belirlenmiştir [Wilks Lambada $(\lambda)=, 971 ; F(1,1242)=7,596, p<0.05]$. Hangi bağımlı değişkenin çok değişkenli anlamlıı̆̆a katkı sağladığını anlamak amacıyla yapılan Bonferonni düzeltmesine göre "cinsiyet" durumu ana etkisi açısından REMM'nin sağlık $(F(1,1242)=9,860 ; p<0,05)$, rekabet $(F(1,1242)=7,464 ; p<0,05)$, vücut ve dış görünüm $(F(1,1242)=18,159 ; p<0,05)$, sosyal ve eğlence $(F(1,1242)=5,190 ; p<0,05)$ ve beceri gelişimi $(F(1,1242)=28,714 ; p<0,05)$ alt boyutlarına ilişkin puan ortalamaları cinsiyet değişkenine göre karşılaştııılığında erkeklerin ortalama puanlarının kadınların ortalama puanlarından daha yüksek olduğu saptanmıştır. Bu durum erkek katılımcıların kadın katılımcılara göre egzersize katıım motivasyonlarında sağlık, rekabet, vücut ve dış görünüm, sosyal ve eğlence, beceri gelişimi puan ortalamalarının pozitif yönde değer alması erkeklerin kadın katılımcılara göre bu faktörleri daha fazla önemsediklerini göstermektedir.

Tablo 2. Yaş Değişkenine Göre MANOVA Sonuçları (REMM)

\begin{tabular}{|c|c|c|c|c|c|}
\hline & & $\begin{array}{l}\text { 17-25 yaş arası } \\
(n=581)\end{array}$ & $\begin{array}{l}\text { 26-35 yaş arası } \\
(n=412)\end{array}$ & $\begin{array}{l}36 \text { yaş ve üzeri } \\
(n=249)\end{array}$ & \\
\hline \multirow{8}{*}{ REMM } & & $\overline{\mathbf{x}} \pm \mathbf{s s}$ & $\overline{\mathbf{x}} \pm \mathbf{s s}$ & $\overline{\mathrm{x}} \pm \mathbf{s s}$ & $p$ \\
\hline & Sağlık & $3,88 \pm, 605$ & $3,78 \pm, 580$ & $3,67 \pm, 557$ & ,000 \\
\hline & Rekabet & $3,66 \pm, 689$ & $3,59 \pm, 617$ & $3,52 \pm, 632$ & ,012 \\
\hline & Vücut ve Dış & $3,79 \pm, 689$ & $3,66 \pm, 671$ & $3,37 \pm, 637$ & ,000 \\
\hline & Görünüm & & & & \\
\hline & Sosyal ve & $3,87 \pm, 632$ & $3,77 \pm, 587$ & $3,67 \pm, 587$ & ,000 \\
\hline & Eğlence & & & & \\
\hline & Beceri Gelişimi & $3,91 \pm, 691$ & $3,79 \pm, 655$ & $3,66 \pm, 621$ & ,000 \\
\hline
\end{tabular}

Yapılan çoklu varyans analizine göre, araştırmaya katılan bireylerin "yaş" değişkenine göre REMM'in tüm alt boyutları üzerindeki temel etkisinin anlamlı olduğu 
belirlenmiştir [Wilks Lambada $(\lambda)=, 941 ; F(2,1242)=7,596, p<0.05$ ]. Hangi bağımlı değişkenin çok değişkenli anlamlıı̆̆a katkı sağladığını anlamak amacıyla yapılan Bonferonni düzeltmesine göre "yaş" durumu ana etkisi açısından REMM'nin sağlık $(F(1,1242)=11,881 ; p<0,05)$, rekabet $(F(2,1242)=4,402 ; p<0,05)$, vücut ve dış görünüm $(F(2,1242)=32,800 ; p<0,05)$, sosyal ve eğlence $(F(1,1242)=10,312$; $p<0,05)$ ve beceri gelişimi $(F(2,1242)=12,204 ; p<0,05)$ alt boyutlarına ilişkin puan ortalamaları yaş değişkenine göre karşılaştırıldığında 17 ile 25 yaş arasındaki katılımcıların egzersize katılım motivasyonlarında sağlık, rekabet, vücut ve dış görünüm, sosyal ve eğlence, beceri gelişimi puan ortalamalarının diğer yaş gruplarına göre daha yüksek olduğu belirlenirken; en düşük puan ortalamasının 36 yaş ve üzerindeki katılımcıların sahip olduğu belirlenmiştir.

Tablo 3. Gelir Düzeyi Değişkenine Göre MANOVA Sonuçları (REMM)

\begin{tabular}{|c|c|c|c|c|c|c|c|}
\hline & & $\begin{array}{l}0-499 \text { TL } \\
(n=60)\end{array}$ & $\begin{array}{l}500-999 \text { TL } \\
(n=67)\end{array}$ & $\begin{array}{l}1000-1499 \\
T L(n=187)\end{array}$ & $\begin{array}{l}1500-1999 \\
\text { TL }(n=309)\end{array}$ & $\begin{array}{l}2000 \text { TL VE } \\
\text { ÜZERİ }(n=619)\end{array}$ & \\
\hline & & $\overline{\mathrm{x}} \pm s s$ & $\overline{\mathrm{x}} \pm \mathbf{s s}$ & $\overline{\mathrm{x}} \pm s s$ & $\overline{\mathrm{x}} \pm \mathrm{ss}$ & $\overline{\mathrm{x}} \pm s s$ & p \\
\hline & Sağlık & $3,69 \pm, 624$ & $3,85 \pm \quad, 601$ & $3,80 \pm \quad, 593$ & $3,81 \pm, 594$ & $3,81 \pm, 588$ &, 596 \\
\hline & Rekabet & $3,55 \pm, 726$ & $3,82 \pm \quad, 617$ & $3,55 \pm \quad, 630$ & $3,67 \pm \quad, 632$ & $3,58 \pm \quad, 668$ & ,009 \\
\hline & Vücut ve & $3,69 \pm, 642$ & $3,75 \pm \quad, 678$ & $3,63 \pm, 669$ & $3,70 \pm \quad, 697$ & 3,64 $\pm \quad, 699$ &, 565 \\
\hline \multirow[t]{4}{*}{ REMM } & Dış & & & & & & \\
\hline & Görünüm & & & & & & \\
\hline & $\begin{array}{l}\text { Sosyal ve } \\
\text { Eğlence }\end{array}$ & $3,69 \pm, 723$ & $3,89 \pm \quad, 593$ & $3,76 \pm, 599$ & $3,80 \pm \quad, 636$ & $3,81 \pm, 596$ & ,346 \\
\hline & $\begin{array}{l}\text { Beceri } \\
\text { Gelişimi }\end{array}$ & $3,66 \pm \quad, 808$ & $3,96 \pm \quad, 581$ & $3,75 \pm \quad, 682$ & $3,78 \pm \quad, 673$ & $3,86 \pm \quad, 658$ & ,018 \\
\hline
\end{tabular}

Yapılan çoklu varyans analizine göre, araştırmaya katılan bireylerin "gelir düzeyi" değişkenine göre REMM'in "rekabet" ve "beceri gelişimi” alt boyutları üzerindeki temel etkisinin anlamlı olduğu belirlenmiştir [Wilks Lambada $(\lambda)=, 964 ; F(4,1242)=$ 2,305, p<0.05]. Hangi bağımlı değişkenin çok değişkenli anlamlılığa katkı sağladığını anlamak amacıyla yapılan Bonferonni düzeltmesine göre "gelir düzeyi" durumu ana etkisi açısından REMM'nin rekabet $(F(4,1242)=3,426 ; p<0,05)$ ve beceri gelişimi $(F(4,1242)=2,991 ; p<0,05)$ alt boyutlarına ilişkin puan ortalamaları gelir düzeyi değişkenine göre karşılaştırıldığında hem rekabet hem de beceri gelişimi alt boyutlarında en yüksek ortalama puanların 500 ile 999 TL gelir düzeyine sahip katılımcıların oluşturduğu tespit belirlenmiştir. 
Güzel, P., Esentaş, M ve Yavaş Tez, Ö. (2020). Rekreatif Egzersiz ve Motivasyon: Fitness Merkezleri Üzerine Amprik Bir Çalışma. Gaziantep Üniversitesi Spor Bilimleri Dergisi, 5(3), 206- 218

Tablo 4. Eğitim Düzeyi Değişkenine Göre MANOVA Sonuçları (REMM)

\begin{tabular}{|c|c|c|c|c|c|c|c|c|}
\hline & & $\begin{array}{l}\text { İlkokul } \\
(n=256)\end{array}$ & $\begin{array}{l}\text { Ortaokul } \\
\text { TL }(n=153)\end{array}$ & $\begin{array}{l}\text { Lise TL } \\
(n=279)\end{array}$ & $\begin{array}{l}\text { Önlisans } \\
\text { TL (n=171) }\end{array}$ & $\begin{array}{l}\text { Lisans } \\
(n=314)\end{array}$ & $\begin{array}{l}\text { Lisansüstü } \\
(n=69)\end{array}$ & \\
\hline & & $\overline{\mathrm{x}} \pm s s$ & $\overline{\mathrm{x}} \pm \mathbf{s s}$ & $\overline{\mathrm{x}} \pm s s$ & $\overline{\mathrm{x}} \pm s s$ & $\overline{\mathrm{x}} \pm \mathrm{ss}$ & $\overline{\mathrm{X}} \pm s s$ & $p$ \\
\hline & Sağlık & $3,76 \pm, 582$ & $3,83 \pm \quad, 563$ & $3,86 \pm \quad, 591$ & $3,72 \pm \quad, 574$ & $3,87 \pm \quad, 619$ & $3,57 \pm \quad, 541$ & ,000 \\
\hline & Rekabet & $3,68 \pm \quad, 638$ & $3,61 \pm, 611$ & $3,56 \pm \quad, 686$ & $3,54 \pm \quad, 628$ & $3,65 \pm \quad, 686$ & $3,48 \pm \quad, 602$ & ,065 \\
\hline & Vücut ve & $3,61 \pm, 692$ & $3,65 \pm \quad, 613$ & $3,72 \pm, 714$ & $3,63 \pm, 651$ & $3,73 \pm \quad, 708$ & $3,35 \pm \quad, 679$ & ,001 \\
\hline \multirow[t]{4}{*}{ REMM } & Dış & & & & & & & \\
\hline & Görünüm & & & & & & & \\
\hline & $\begin{array}{l}\text { Sosyal ve } \\
\text { Eğlence }\end{array}$ & $3,84 \pm \quad, 619$ & $3,79 \pm \quad, 625$ & $3,85 \pm \quad, 628$ & $3,71 \pm, 564$ & $3,84 \pm \quad, 617$ & $3,52 \pm \quad, 529$ & ,001 \\
\hline & $\begin{array}{l}\text { Beceri } \\
\text { Gelişimi }\end{array}$ & $3,68 \pm, 691$ & $3,74 \pm \quad, 663$ & 3,93 \pm ,655 & $3,81 \pm \quad, 625$ & $3,91 \pm, 685$ & $3,68 \pm \quad, 603$ & ,000 \\
\hline
\end{tabular}

${ }^{*} \mathrm{p}<.05$

Yapılan çoklu varyans analizine göre, araştırmaya katılan bireylerin "eğitim düzeyi" değişkenine göre REMM'in "rekabet" alt boyutu hariç tüm alt boyutlar üzerindeki temel etkisinin anlamlı olduğu belirlenmiştir [Wilks Lambada $(\lambda)=, 917 ; F(5,1242)=$ $4,310, p<0.05]$. Hangi bağımlı değişkenin çok değişkenli anlamlıı̆a katkı sağladığını anlamak amacıyla yapılan Bonferonni düzeltmesine göre "eğitim düzeyi" durumu ana etkisi açısından REMM'nin sağlık $(F(5,1242)=4,513 ; p<0,05)$, vücut ve dış görünüm $(F(5,1242)=4,333 ; p<0,05)$, sosyal ve eğlence $(F(5,1242)=4,343 ; p<0,05)$ ve beceri gelişimi $(F(5,1242)=6,175 ; p<0,05)$ alt boyutlarına ilişkin puan ortalamaları eğitim düzeyi değişkenine göre karşılaştırıldığında "sağlık" ile "vücut ve dış görünüm" alt boyutlarında en yüksek ortalama puanların lisans düzeyindeki katılımcıların sahip olduğu; "sosyal ve eğlence" ile "beceri gelişimi" alt boyutlarında en yüksek ortalama puanların ise lise düzeyindeki katılımcıların sahip olduğu belirlenmiştir.

Tablo 5. Egzersiz Türü Değişkenine Göre MANOVA Sonuçları (REMM)

\begin{tabular}{lllll}
\hline & \multicolumn{3}{l}{ Fitness $(\mathbf{n}=\mathbf{9 4 3})$} & \multicolumn{2}{l}{ CrossFit (n=299) } & \\
\hline & Sağlık & $\overline{\mathbf{x}} \pm \mathbf{s s}$ & $\overline{\mathbf{x}} \pm \mathbf{s s}$ & $\mathbf{p}$ \\
& Rekabet & $3,85 \pm, 576$ & $3,64 \pm, 616$ &, 000 \\
\multirow{2}{*}{ REMM } & $3,61 \pm, 664$ & $3,59 \pm, 633$ &, 668 \\
& Vücut ve Dış Görünüm & $3,71 \pm, 685$ & $3,50 \pm, 684$ &, 000 \\
& Sosyal ve Eğlence & $3,84 \pm, 611$ & $3,68 \pm, 608$ &, 000 \\
& Beceri Gelişimi & $3,86 \pm, 660$ & $3,70 \pm, 692$ &, 000 \\
\hline
\end{tabular}


Yapılan çoklu varyans analizine göre, araştırmaya katılan bireylerin "egzersiz türü" değişkenine göre REMM'in "rekabet" alt boyutu hariç tüm alt boyutlar üzerindeki temel etkisinin anlamlı olduğu belirlenmiştir [Wilks Lambada $(\lambda)=, 966 ; F(1,1242)=$ 8,742, p<0.05]. Hangi bağımlı değişkenin çok değişkenli anlamlılığa katkı sağladığını anlamak amacıyla yapılan Bonferonni düzeltmesine göre "egzersiz türü" durumu ana etkisi açısından REMM'nin sağlık $(F(1,1242)=28,931 ; p<0,05)$, vücut ve dış görünüm $(F(1,1242)=20,858 ; p<0,05)$, sosyal ve eğlence $(F(1,1242)=14,099 ; p<0,05)$ ve beceri gelişimi $(F(1,1242)=13,924 ; p<0,05)$ alt boyutlarına ilişkin puan ortalamaları egzersiz türü değişkenine göre karşılaştırıldığında REMM'in tüm alt boyutlara ilişkin puan ortalamalarının fitness ile uğraşan katılımcıların crossfit ile uğraşan katılımcıların puan ortalamalarından daha yüksek olduğu belirlenmiştir.

Tablo 6. Egzersiz Süresi Değişkenine Göre MANOVA Sonuçları (REMM)

\begin{tabular}{|c|c|c|c|c|c|c|c|}
\hline & & $\begin{array}{l}\text { 1aydan az } \\
(n=195)\end{array}$ & $\begin{array}{l}1 \text { ile } 6 \text { ay } \\
\text { arası } \\
(n=521)\end{array}$ & $\begin{array}{l}6 \text { ile } 12 \text { ay } \\
\text { arası }(n=269)\end{array}$ & $\begin{array}{l}12 \text { ile } 18 \text { ay } \\
\text { arası }(n=172)\end{array}$ & $\begin{array}{l}24 \text { ay ve üzeri } \\
(n=85)\end{array}$ & \\
\hline & & $\overline{\mathrm{x}} \pm s s$ & $\overline{\mathbf{x}} \pm \mathbf{s s}$ & $\overline{\mathbf{x}} \pm s s$ & $\overline{\mathbf{x}} \pm \mathbf{s s}$ & $\overline{\mathbf{x}} \pm s s$ & $p$ \\
\hline & Sağlık & $3,85 \pm \quad, 615$ & $3,74 \pm \quad, 549$ & $3,86 \pm, 593$ & $3,82 \pm \quad, 628$ & $3,85 \pm \quad, 692$ & ,046 \\
\hline & Rekabet & $3,68 \pm, 723$ & $3,57 \pm \quad, 598$ & $3,61 \pm, 677$ & $3,60 \pm, 693$ & $3,64 \pm \quad, 698$ & ,436 \\
\hline & Vücut ve & $3,68 \pm \quad, 694$ & $3,57 \pm \quad, 647$ & $3,77 \pm \quad, 727$ & $3,68 \pm \quad, 725$ & $3,76 \pm \quad, 688$ & ,001 \\
\hline \multirow[t]{4}{*}{ REMM } & Dış & & & & & & \\
\hline & Görünüm & & & & & & \\
\hline & $\begin{array}{l}\text { Sosyal ve } \\
\text { Eğlence }\end{array}$ & $3,89 \pm \quad, 669$ & $3,74 \pm \quad, 565$ & $3,84 \pm \quad 614$ & $3,79 \pm \quad, 658$ & $3,85 \pm \quad, 643$ & ,030 \\
\hline & $\begin{array}{l}\text { Beceri } \\
\text { Gelişimi }\end{array}$ & $3,86 \pm \quad, 658$ & $3,72 \pm \quad, 648$ & $3,94 \pm \quad 650$ & $3,79 \pm \quad, 745$ & $3,99 \pm \quad, 661$ & ,000 \\
\hline
\end{tabular}

${ }^{\star} \mathrm{p}<.05$

Yapılan çoklu varyans analizine göre, araştırmaya katılan bireylerin "egzersiz süresi" değişkenine göre REMM'in "rekabet" alt boyutu hariç tüm alt boyutlar üzerindeki temel etkisinin anlamlı olduğu belirlenmiştir [Wilks Lambada $(\lambda)=, 963 ; F(4,1242)=$ 8,742 , p<0.05]. Hangi bağımlı değişkenin çok değişkenli anlamlılığa katkı sağladığını anlamak amacıyla yapılan Bonferonni düzeltmesine göre "egzersiz süresi" durumu ana etkisi açısından REMM'nin sağlık $(F(4,1242)=2,431 ; p<0,05)$, vücut ve dış görünüm $(F(4,1242)=4,421 ; p<0,05)$, sosyal ve eğlence $(F(4,1242)=2,681 ; p<0,05)$ ve beceri gelişimi $(F(4,1242)=6,624 ; p<0,05)$ alt boyutlarına ilişkin puan ortalamaları egzersiz süresi değişkenine göre karşılaştırıldığında REMM'in 24 ay ve üzerinde egzersize katılım gösteren katılımcıların "vücut ve dış görünüm” ile "beceri gelişimi” 
alt boyutlarına ilişkin puan ortalamalarının daha yüksek olduğu; "sağlık" alt boyutunda 6 ile 12 ay arasında katılım gösteren katılımcıların en yüksek puan ortalamasına sahip olduğu; "sosyal ve eğlence" alt boyutunda ise 1 aydan daha az katılım gösteren katılımcıların sahip olduğu belirlenmiştir.

Tablo 7. Besin Takviyesi Değişkenine Göre MANOVA Sonuçları (REMM)

\begin{tabular}{lllll}
\hline & Evet $(\mathbf{n}=485)$ & Hayır $(\mathbf{n = 7 5 7 )}$ & \\
\hline & Sağlık & $\overline{\mathbf{x}} \pm \mathbf{s s}$ & $\overline{\mathbf{x}} \pm \mathbf{s s}$ & $\mathbf{p}$ \\
& $3,81 \pm, 591$ & $3,80 \pm, 593$ &, 652 \\
& Rekabet & $3,68 \pm, 646$ & $3,56 \pm, 659$ &, 003 \\
\multirow{2}{*}{ REMM } & Vücut ve Dış & $3,72 \pm, 663$ & $3,63 \pm, 705$ &, 026 \\
& Görünüm & & & \\
& Sosyal ve Eğlence & $3,83 \pm, 612$ & $3,78 \pm, 613$ &, 111 \\
& Beceri Gelişimi & $3,87 \pm, 661$ & $3,79 \pm, 676$ &, 043 \\
\hline
\end{tabular}

${ }^{*} p<.05$

Yapılan çoklu varyans analizine göre, araştırmaya katılan bireylerin "besin takviyesi" değişkenine göre REMM'in "sağlık" ile "sosyal ve eğlence" alt boyutları hariç tüm alt boyutlar üzerindeki temel etkisinin anlamlı olduğu belirlenmiştir [Wilks Lambada $(\lambda)=$ ,987; $F(1,1242)=3,315, p<0.05]$. Hangi bağımlı değişkenin çok değişkenli anlamlılığa katkı sağladığını anlamak amacıyla yapılan Bonferonni düzeltmesine göre "besin takviyesi" durumu ana etkisi açısından REMM'nin rekabet $(F(1,1242)=9,125$; $p<0,05)$, vücut ve dış görünüm $(F(1,1242)=4,984 ; p<0,05)$ ve beceri gelişimi $(F(1,1242)=4,108 ; p<0,05)$ alt boyutlarına ilişkin puan ortalamaları besin takviyesi değişkenine göre karşılaştıııldığında REMM'in tüm alt boyutlara ilişkin puan ortalamalarının besin takviyesi alan katılımcıların besin takviyesi almayan katılımcılara göre daha yüksek olduğu belirlenmiştir.

\section{Tartışma ve Sonuç}

$\mathrm{Bu}$ araştırmada, rekreatif egzersiz amaçı katılımında etkili olan motivasyon faktörlerinin fitness merkezi katılımcıları üzerindeki etkilerinin incelenmesi gerçekleştirilmiştir. MANOVA analiz sonuçları, cinsiyet ve yaş değişkeninin "REMM" nin tüm alt boyutlarında (sağlık, rekabet, vücut ve dış görünüm, sosyal ve eğlence, beceri gelişimi) temel etkisinin anlamlı olduğu belirlenmiştir. Erkek katılımcıların kadın katılımcılara göre egzersize katılım motivasyonlarında sağlık, rekabet, vücut ve dış görünüm, sosyal ve eğlence, beceri gelişimi puan ortalamalarının pozitif yönde değer alması erkeklerin kadın katılımcılara göre bu faktörleri daha fazla önemsediklerini 
göstermektedir. Cinsiyet değişkeni bireyin serbest zaman etkinliklerine katıım motivasyonu üzerinde önemli bir belirleyici olup (Lapa ve ark., 2012), kadın ve erkeklerin farklı amaçlar ve beklentiler ile fitness merkezlerine yöneldikleri bilinmektedir (Güdül, 2008; Afthinos ve ark., 2005). Ağyar ve ark. (2012) yılında yapmış oldukları bir araştırmada, sportif rekreasyona katııında cinsiyete değişkenine göre erkeklerin kadınlara göre spora daha fazla ilgi duyduklarını bulmuşlardır. Bu sonucun bu araştırma sonuçları ile örtüşmekte olduğu görülmektedir.

Yaş değişkenine göre karşılaştırıldığında 17 ile 25 yaş arasındaki katııımcıların egzersize katılım motivasyonlarında sağlık, rekabet, vücut ve dış görünüm, sosyal ve eğlence, beceri gelişimi puan ortalamalarının diğer yaş gruplarına göre daha yüksek olduğu belirlenirken; en düşük puan ortalamasının 36 yaş ve üzerindeki katııımcıların sahip olduğu belirlenmiştir. 17-25 yaş grubundaki katıımcıların rekreasyonel hizmet sunan fitness merkezlerinden beklentilerini karşılamış oldukları söylenebilir. Literatürde yer alan bazı çalışmalarda çalışmamızın sonuçları ile örtüşmektedir (Coleman ve Isohala 1993; Patry ve ark. 2007; Çuhadar ve ark. 2019). Rekreasyonel hizmet sunan fitness merkezlerinin yaş gruplarının beklentilerini saptayarak, yaş grubuna, özel programlarda kişiye özel programlar hazırlayarak motivasyonlarının daha fazla artmasına katkı sağlaması mümkündür. Motivasyonel memnuniyet arttıkça, fitness merkezini tercih eden üye sayısının da artacak olması muhtemeldir.

Sağıroğlu ve Ayar (2017) yapmış oldukları çalışmalarında REMM ölçeğinin sağlık, rekabet, sosyal/eğlence ve beceri gelişimi alt boyutları ile egzersiz süresi arasında pozitif yönde anlamlı bir ilişki tespit etmişlerdir. Bu çalışma sonucunda da 24 ay ve üzerinde egzersize katııı gösteren katıımcıların "vücut ve dış görünüm" ile "beceri gelişimi" alt boyutlarına ilişkin puan ortalamalarının daha yüksek olduğu; "sağlık" alt boyutunda 6 ile 12 ay arasında katıım gösteren katıımcıların en yüksek puan ortalamasına sahip olduğu; "sosyal ve eğlence" alt boyutunda ise 1 aydan daha az katıım gösteren katılımcıların sahip olduğu belirlenmiştir. Yetim ve Argan (2017) tarafından fitness merkezi üyelerinin ilgilenmeleri ile ilgili yapılmış çalışmalarında serbest zaman ilgilenimi faktör ortalamaları değerlendirildiğinde sağlık ve fitness ilk sırada yer aldığı tespit edilmiştir. Bu sonuç bu araştırmanın sonuçlarını destekler niteliktedir. Araştırma sonuçları değerlendirildiğinde fitness merkezi katıımcılarının kısa vadede algıladıkları hizmetlerden beklentileri sağıı iken, uzun vadede vücut ve dış görünüm denilebilir. Sağılıları daha iyi oldukça yaşam kaliteleri de artacağı düşünülmektedir. Bireylerin hem kendilerini beğenmeleri hem de etraflarındaki kişiler 
tarafından onanma, beğenilme oranları artıkça fitness merkezlerine gitmelerinde motivasyonlarını daha artırdığı söylenebilir.

Sportif etkinliklere katılım bireyleri birçok açıdan olumlu yönde etkilemektedir, bu kazanımlardan birisi de psikolojik etkilerdir (Güner, 2015; Eraslan ve Aydoğan, 2016). Bu araştırma sonucunda, rekreatif egzersiz amaçlı katılımda bireysel farklılıkların motivasyon faktörleri üzerinde etkisi olduğu ve bu farklılıkların katılımcıların negatif ya da pozitif tutumlarından kaynaklandığı söylenebilir.

$\mathrm{Bu}$ araştırma sonucunda rekreasyonel egzersiz hizmeti sunan fitness merkezlerinin hitap ettikleri üyelerinin beklentilerinin hizmet kalitesinin sağlanması gerekliliği olarak, nasıl bir ortamda bulunmak istedikleri, ne tür aktivite çeşitliliği olmasını bekledikleri tespit edilip, yaş, cinsiyet, etkinliğe katım süresi gibi değişkenlerde göz önüne alınarak üyelerin motivasyonlarını artırıcı etkinlik hizmeti sunmaları önerilmektedir.

\section{Kaynaklar}

Afthinos Y.,Theodorakis N.D., Nassis P. (2005). Customers' expectations of service in Greek fitness centers: gender, age, type of sportcenter, and motivation differences. Managing Service Quality: An International Journal, 15(3), 245-258. Ağyar, E., Kalkan, A., Çerez, H. (2012). Sağlık çalışanlarının sportif rekreasyona katılımlarının incelenmesi (Antalya Araştırma ve Eğitim Hastanesi Örneği). I. Rekreasyon Araştırmaları Kongresi, Kemerl Antalya, 15-29.

Aydın, İ., \& Yaşartürk, F. (2017). Fitnes katılımcıların rekreasyonel etkinliklere yönelik motivasyon düzeylerinin çeşitli değişkenlere göre incelenmesi. Uluslararası Kültürel ve Sosyal Araştırmalar Dergisi (UKSAD), 3(Special Issue 2), 142-152.

Büyüköztürk, Ş., Çakmak, E. K., Akgün, Ö. E., Karadeniz, Ş., \& Demirel, F. (2017). Bilimsel araştırma yöntemleri. Pegem Atıf İndeksi, 1-360.

Broadhurst, R. (2001). Managing environments for leisure and recreation. Psychology Press.

Broughton, K.,\&Beggs, B. A. (2007). Leisure satisfaction of older adults. Activities, Adaptation \&Aging, 31(1), 1-18.

Brunet, J., \& Sabiston, C. M. (2011). Exploring motivation for physical activity across the adult lifespan. Psychology of Sport and Exercise, 12(2), 99-105.

Carroll, B.,\&Alexandris, K. (1997). Perception of constraints and strength of motivation: Their relationship to recreational sport participation in Greece. Journal of Leisure Research, 29(3), 279-299. 
Coleman, D.,\& Iso-Ahola, S. E. (1993). Leisure and health: The role of social support and self-determination. Journal of Leisure Research, 25(2), 111-128.

Çaglar, E., Canlan, Y., \& Demir, M. (2009). Recreational exercise motives of adolescents and young adults. Journal of Human Kinetics, 22, 83-89.

Çuhadar, A., Yusuf, E. R., Demirel, M., \& Demirel, D. H. (2019). Bireyleri rekreasyonel amaçlı egzersize motive eden faktörlerin incelenmesi. Spormetre Beden Eğitimi ve Spor Bilimleri Dergisi, 17(3), 153-161. Doi: 10.33689/spormetre.562233.

Demirel, H. (2013). Rekreasyonel spor/fitness programı sunan işletmelerde hizmet kalitesi. Doktora Tezi, Gazi Üniversitesi, Sağlık Bilimleri Enstitüsü, Ankara.

Dinç, S.C., ve Yavaş-Tez, Ö. (2019) Rekreasyonel egzersize motivasyon ölçeğii"nin (REMM) çocuk sporcular için geçerlik ve güvenirliğinin incelenmesi: Kısa form. Türk Spor Bilimleri Dergisi, 2(1), 74-85.

Eraslan, M., Aydoğan, H . (2016). Vücut geliştirme ve fitness merkezinde spor yapan bireylerin beden bölgelerinden hoşnut olma düzeylerinin yaş ve cinsiyet değişkenlerine göre incelenmesi. CBÜ Beden Eğitimi ve Spor Bilimleri Dergisi, $11(2)$.

Esentaş, M. (2018). Metaphorical perceptions of the academicians working in the field of recreation regarding the concept of "recreation". Journal of Education and Training Studies, 6(12), 42-47.

Güdül N. (2008). Fitness salonlarına giden bireylerin beklentileri. Yüksek Lisans Tezi, Afyon Kocatepe Üniversitesi, Sağlık Bilimleri Enstitüsü. Afyon.

Güner, B. (2015). Kadınların spor ve serbest zaman etkinliklerine katılım sorunlarının değerlendirilmesi. Uluslararası Spor Bilimleri Dergisi, 1(1). Jel Code: I1, I10, L83.

Gürbüz, B., Aşçı, F. H., \& Çelebi, M. (2006, November). The reliability and validity of theTurkish Version of the recreational exercise motivation measure. In The 9th International Sports Sciences Congress (3-5 November), Congress Proceedings. Muğla.

Hamer, M., Karageorghis, C., \& Vlachopoulos, S. (2002). Motives for exercise participation as predictors of exercise dependence among endurance athletes.Journal of Sports Medicine and Physical Fitness, 42,233-238.

Kaya, E. (2019). Investigation of motivation levels of individuals doing fitness and kickbox for recreative activity purpose in terms of some variables. Journal of Education and Training Studies, 7(10), 11-18. 
Lapa T.Y., Ağyar E., Bahadır Z. (2012). Yaşam tatmini, serbest zaman motivasyonu, serbest zaman katılımı: beden eğitimi ve spor öğretmenleri üzerine bir inceleme (Kayseri ili örneği). Spormetre Beden Eğitimi ve Spor Bilimleri Dergisi, 10(2), 53-59.

Mutlu, İ., Yılmaz, B., Güngörmüş, H. A., Sevindi, T., \& Gürbüz, B. (2011). Bireyleri rekreasyonel amaçlı egzersize motive eden faktörlerin çeşitli değişkenlere göre karşılaştırılması. Selçuk Üniversitesi Beden Eğitimi ve Spor Bilim Dergisi, 13(1), 54-61.

Tezcan NM. (1994). Boş zamanları değerlendirme sosyolojisi. Ankara: Atilla Kitabevi.

Türk Dil Kurumu (2020) Erişim Tarihi: 28.03.2020 https://sozluk.tdk.gov.tr/

Patry, D. A.,Blanchard, C. M., \& Mask, L. (2007). Measuring university students' regulatory leisure copaing styles: Planned breathers or avoidance? Leisure Sciences, 29, 247-265. doi: https://doi.org/10.1080/ 01490400701257963

Roberts K. (2006). Leisure in contemporary society (2. baskı) Wallingford, UK: Cabi.

Rogers, H. E. (2000). Development of a recreational exercise motivation questionnaire (Doctoral dissertation, Victoria University of Technology).

Rogers, H. E., and Morris, T. (2003). An overview of the development and validation of the recreational exercise motivation measure (REMM), in Proceedings of the 11th European Congress of Sport Psychology: New approaches to Exercise and Sport Psychology: Theories, Methods and Applications, ed. R. Stelter (Copenhagen: University of Copenhagen).

Sağıroğlu, İ.,\& Ayar, H. (2017). Fitness ve crossfit merkezlerine rekreatif egzersiz amaçı katılımda etkili olan motivasyon faktörlerinin incelenmesi. The Journal of International Anatolia Sport Science, 2 (2), 167-179.

Şahin, C. K., Akten, S., \& Erol, U. E. (2011). A study to determine recreational participation tendency of the eğirdir vocational school students. Artvin Çoruh Üniversitesi Orman Fakültesi Dergisi, 10(1), 62-71.

Yetim, G. ve Argan, M. (2018). Boş zaman ilgilenim faktörleri ile fitness merkezine yönelik tatmin ve sadakat arasındaki ilişki. Anadolu Üniversitesi Sosyal Bilimler Dergisi, 18 (1) , 49-62. DOI: 10.18037/ausbd.550625.

Yılmaz, H., \& Çavaş, P. H. (2007). Fen öğrenimine yönelik motivasyon ölçeğinin geçerlik ve güvenirlik çalışması. İlköğretim online, 6(3), 430-440. 